\section{BEHAVIOURAL SCIENCE}

\section{Burnout intervention among Dutch dentists: long-term effects}

Te Brake JHM, Gorter RC et al. Eur J Oral Sci 2001; 109: 380-387

Some subjects at risk of burnout may reduce it on their own initiative.

Burnout in dentists is primarily a response to chronic stress, involving emotional exhaustion and a negative, cynical attitude towards patients. In 1998, a group of 171 dentists identified as at risk of burnout was offered an intervention programme, and 19 accepted (E group); the others were potential control (C) subjects. The E programme comprised individual counselling and group workshop sessions. Among the controls, some had initiated remedial approaches of their own $(\mathrm{C}+)$, and others had not (C-).

One month after the programme, there were improvements in burnout in the E and C+ groups. By $1 \mathrm{yr}$, all 3 measured burnout components (emotional exhaustion, depersonalization and personal accomplishment) were improved only in the $\mathrm{C}+$ group. The authors discuss these findings and suggest that the $\mathrm{C}+$ group had effective coping styles and perhaps felt in greater control of their work environment, while the E group might have required more personal counselling.

\section{PERIODONTICS; PROSTHODONTICS}

\section{The effect of removable partial dentures on periodontal health of abutment and non-abutment teeth}

Zlatarić DK, Čelebić A et al. J Periodontol 2002; 73: 137-144

Abutment teeth showed more disease.

In this study in a Croatian university prosthodontic department, natural abutment, crown abutment and non-abutment teeth were examined in 205 patients who had worn 123 maxillary and 138 mandibular removable partial dentures (RPDs) for $1-10 \mathrm{yrs}$.

In patients with older RPDs and in those wearing them day and night, abutment teeth had more plaque, gingivitis and calculus, and greater probing depths and recession. In subjects with mucosa-borne dentures covering the gingival margin, gingivitis, calculus and probing depth scores were greater. One surprising finding was that smokers had greater gingival inflammation.

Certain aspects of denture design were found to affect the health of abutment teeth. The authors conclude that unless RPDs are well-designed and good $\mathrm{OH}$ instituted, they may cause increased periodontal damage.

\section{BEHAVIOURAL SCIENCE}

\section{Oro-facial pain in the community: prevalence and associated impact}

Macfarlane TV, Blinkhorn AS et al. Community Dent Oral Epidemio/2002; 30: 52-60

A quarter of an adult population experienced this form of pain, but only half of them sought treatment.

A random sample of 4000 patients aged 16-65 yrs in a general medical practice were invited to participate in this study and 2504 did so, an adjusted response rate of 74\%. Over a 1 month period, $26 \%$ had experienced some form of orofacial pain. The commonest site was around the eyes (293 subjects), followed by the temples (240), the area in front of the ears (150), the TMJ (157), and various areas of the mouth and cheeks.

Just under half of subjects had sought advice on their pain, $57 \%$ of these from their medical practitioner and 51\% from their dental practitioner. Two-thirds had taken medication, and $17 \%$ had taken time off work or had been unable to carry out their normal activities. Prevalence of pain was greater in women and younger age groups. The authors conclude that the burden of this pain is likely to be borne in part by the community, since more than half of subjects did not seek help.

\section{DENTAL TRAUMA}

\section{Comparison of a new dental trauma splint device (TTS) with three commonly used splinting techniques \\ von Arx T, Filippi A et al. Dent Traumato/ 2001; 17: 266-274}

Resin splints appeared most effective, but the new system was the quickest to apply.

This study compared 4 types of splint in 10 volunteers. Four healthy maxillary incisors were splinted for 1 week at a time on the labial surface with the following splint systems in random order: wire-composite (WCS), bonded orthodontic button brackets with braided wire (BS), resin bonded across all 4 teeth (RS) and the new bonded titanium trauma splint (TTS) shaped as a series of connected rhombuses. Before and after splint application, tooth mobility was assessed with the Periotest impact system.

Subjects maintained excellent oral hygiene throughout the study. The greatest splint effect (reduction of lateral mobility) was achieved with RS, and was significantly greater than in TTS and WCS. There were no significant differences in changes of vertical mobility after splinting. Splint application was significantly quicker with TTS (mean $8.6 \mathrm{~min}$ ) than all other systems, and TTS removal was quickest (3.7 $\mathrm{min})$. 